\title{
DISCLAIMER
}

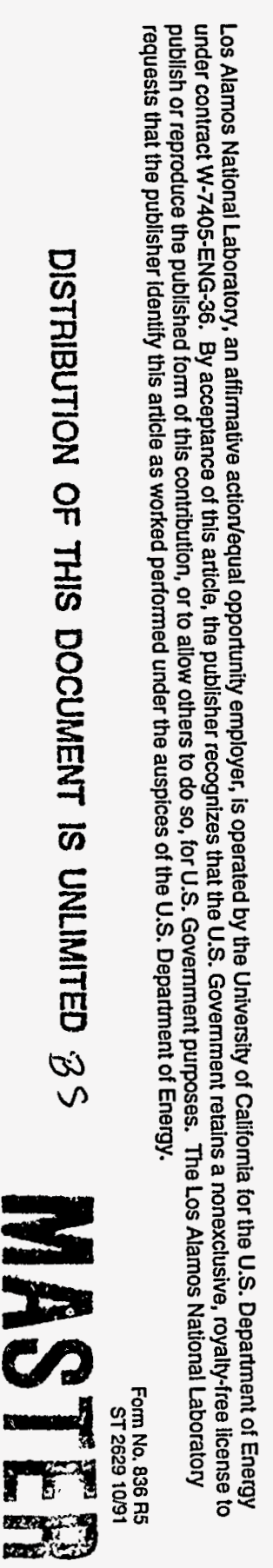

This report was prepared as an account of work sponsored by an agency of the United States Government. Neither the United States Government nor any agency thereof, nor any of their employees, makes any warranty, express or implied, or assumes any legal liability or responsibility for the accuracy, completeness, or usefulness of any information, apparatus, product, or process disclosed, or represents that its use would not infringe privately owned rights. Reference herein to any specific commercial product, process, or service by trade name, trademark, manufacturer, or otherwise does not necessarily constitute or imply its endorsement, recommendation, or favoring by the United States Government or any agency thereof. The views and opinions of authors expressed herein do not necessarily state or reflect those of the United States Government or any agency thereof.
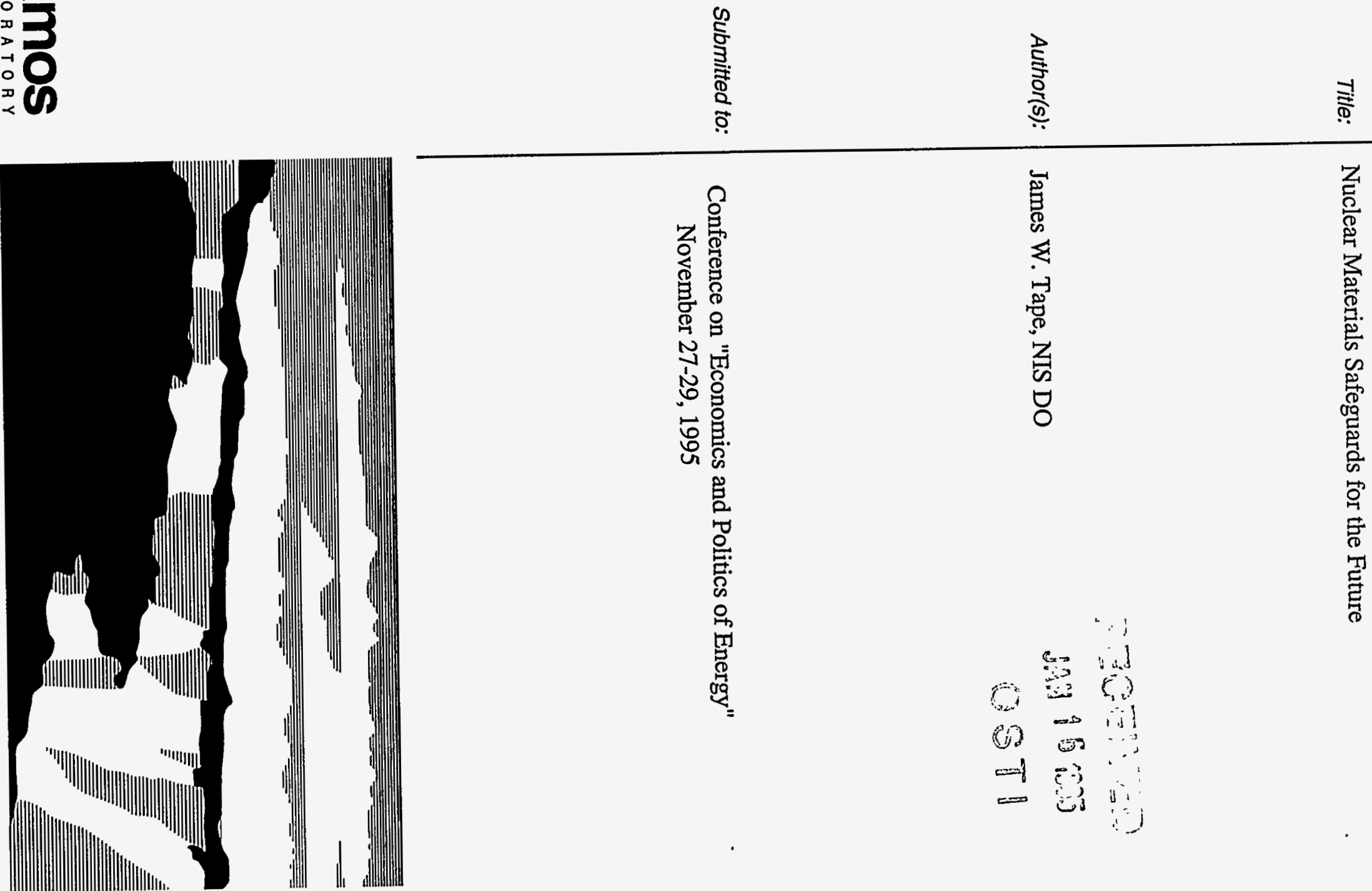

包 


\author{
Nuclear Materials Safeguards for the Future ${ }^{1}$ \\ J. W. Tape \\ Los Alamos National Laboratory
}

\begin{abstract}
Basic concepts of domestic and international safeguards are described, with an emphasis on safeguards systems for the fuel cycles of commercial power reactors. Future trends in institutional and technical measures for nuclear materials safeguards are outlined. The conclusion is that continued developments in safeguards approaches and technology, coupled with institutional measures that facilitate the global management and protection of nuclear materials, are up to the challenge of safeguarding the growing inventories of nuclear materials in commercial fuel cycles in technologically advanced States with stable governments that have signed the nonproliferation treaty. These same approaches also show promise for facilitating international inspection of excess weapons materials and verifying a fissile materials cutoff convention.
\end{abstract}

\title{
Introduction
}

The management, protection, and control of nuclear materials to prevent their unauthorized use (safeguards) is one of a few remaining technical barriers to the proliferation of nuclear weapons. National (also called domestic) safeguards and security are designed to protect nuclear materials from misuse, including diversion and theft by adversaries of the State operating at a subnational level but possibly including terrorism sponsored by an external state. Domestic safeguards and security systems are the first line of defense in controlling and protecting nuclear materials and are a fundamental building block of international arrangements for managing and controlling nuclear materials. International safeguards are designed to verify that States are meeting their nonproliferation commitments to place nuclear materials and facilities under inspection through bilateral, regional, or multilateral arrangements.

The nuclear materials of interest to proliferation can be divided into three categories as shown in figure 1; materials in the five nuclear weapons states defined by the nuclear nonproliferation treaty (NPT), materials under international safeguards in civilian applications, and materials outside international safeguards. New initiatives to address nuclear materials control issues outside the realm of traditional safeguards include the U.S. offer to place excess weapons materials under some form of international inspection and the proposed fissile materials production cutoff convention, which would ban future production of fissile materials for weapons purposes or outside international safeguards.

1 Portions of this paper are drawn from the report of the Subpanel on Safeguards and Security found in the American Nuclear Society Special Panel Report "Protection and Management of Plutonium," (August 1995). 


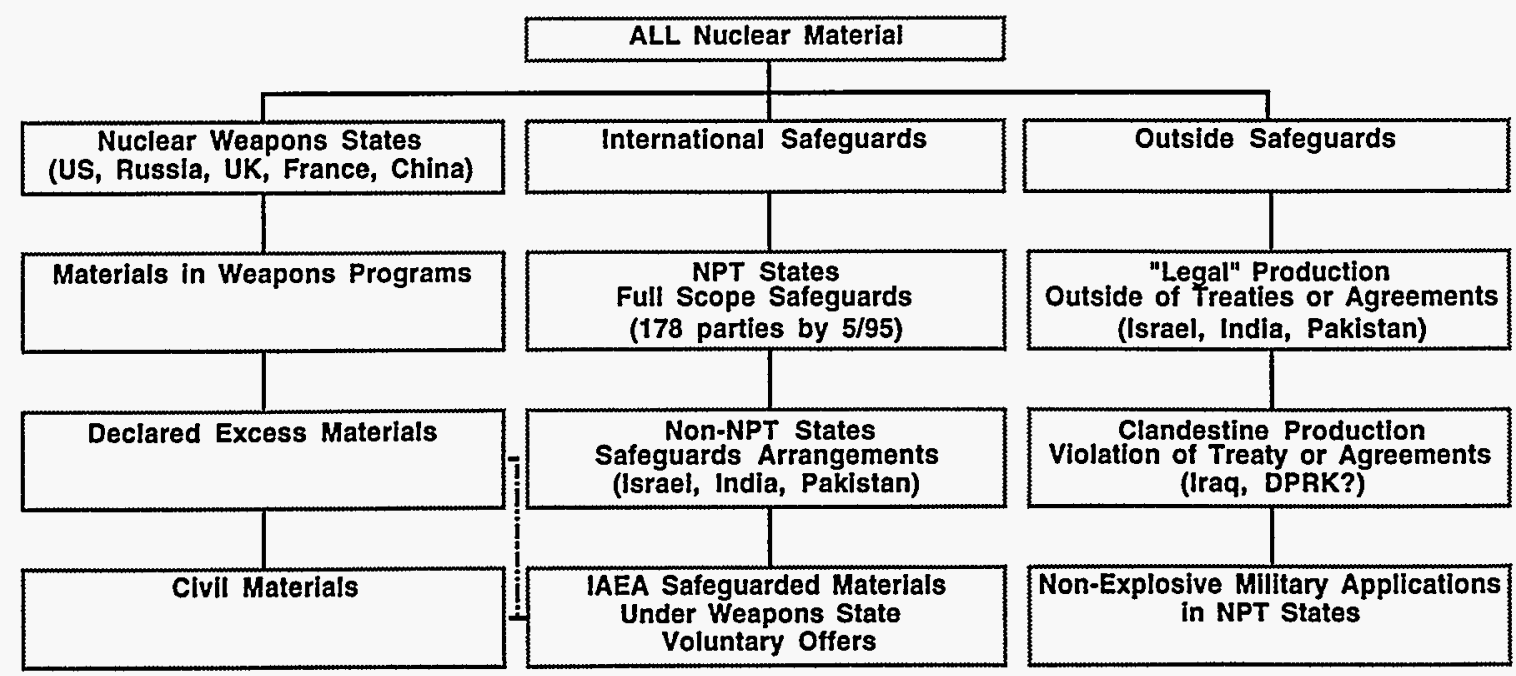

Fig. 1. Schematic breakdown of global nuclear materials into three broad categories in nuclear weapons states, under international safeguards, and outside safeguards.

Because of their value and sensitivity, all nuclear materials are likely to be under some form of domestic safeguards to protect against theft and unauthorized use. Domestic safeguards systems are usually described in terms of three elements: physical protection, materials control, and materials accounting. In practice, materials control and accounting activities are often managed as part of an overall materials control and accounting (MC\&A) system.

Materials accounting and containment and surveillance (C/S) are fundamental elements of international safeguards; however, international safeguards are being strengthened to include broad measures that go well beyond these two traditional safeguards measures to include improved access to information and sites. The primary goal of the strengthening measures is to improve the International Atomic Energy Agency's (IAEA) ability to detect undeclared nuclear materials or facilities in countries that have signed the NPT. Although advancements in traditional IAEA safeguards are usually evolutionary, some of the new measures to be included in strengthened safeguards are more revolutionary and follow directly from the lessons learned in Iraq following the Gulf War.

International safeguards have no direct equivalent of physical protection (considered the responsibility of the State); however, the IAEA does support the development of common standards for the protection of nuclear materials and the dissemination of knowledge about physical protection measures and systems. The United States government also encourages the transfer of physical protection technology and methods by means of bilateral discussions and technology transfer programs. Furthermore, modern integrated systems that combine features of $\mathrm{C} / \mathrm{S}$, process monitoring, and continuous, unattended assay of materials can provide timely warning of anomalous conditions in facilities under international safeguards and thus perform some of the prompt-detection functions of a physical protection system. 
Integrated systems are the key to successful safeguards for either domestic or international applications. Defense-in-depth is a fundamental principle of design that is often misunderstood by those who attempt the very difficult task of assessing the effectiveness of safeguards systems. Timely detection of diversion might be, for example, the result of surveillance (by humans or sensors), near-real-time accounting systems, process monitoring, portal monitors, access control systems, or intrusion detectors. Diversion is deterred by all these elements plus an effective accounting system that can provide an audit trail confirming that materials are in fact missing from a facility or process. No one element is the "most important"; they must work together for good materials safeguards.

Safeguards systems designed with a defense-in-depth approach can reduce the risk of diversion or theft from declared fuel cycles to acceptable levels for reasonable costs. Modern domestic safeguards and security systems employed by facilities under regulation by strong, stable governments, when coupled with strong response elements, are commonly viewed by safeguards professionals as providing adequate protection against subnational threats. In this regard, it is important for safeguards systems design to take into account the local differences in threats to nuclear materials and facilities. Concern remains for how to protect nuclear materials in unstable parts of the world and for how to protect against the determined State proliferator.

In considering the role of safeguards in the nonproliferation regime and their relationship to the growth of civilian nuclear power, it is important to recognize that the route to proliferation has been, and is most likely to remain, the use of clandestine, dedicated weapons production facilities either outside any treaty agreements or in violation of agreements. Thus for the nuclear power fuel cycle, the role of domestic safeguards is to maintain sufficient assurance that materials are protected from subnational threats, and the role of international safeguards is to provide assurance that declared materials have not been diverted for nuclear explosives or purposes. unknown and that (declared) fuel cycle facilities are not misused for unsafeguarded production of weapons-usable materials. The possibility of clandestine production of nuclear weapons materials has little bearing on safeguards for the nuclear power fuel cycle ${ }^{2}$ except to note that safeguards systems need only be good enough to motivate the determined proliferator to produce materials directly rather than diverting them from safeguarded facilities.

Safeguards must be an integral part of the nonproliferation regime that considers the motives of States or terrorist groups, their capabilities, the number and kinds of nuclear devices they desire, and the global availability of all weapons-usable nuclear materials, not just plutonium. A balanced approach that considers all these factors will provide guidance as to the required performance and cost of safeguards systems. Proposals to eliminate commercial nuclear power, restrict the use of plutonium, and/or to dispose of nuclear materials must be evaluated in this broader context.

\section{Trends for the Future}

2 The ANS Special Panel report contains an extensive discussion of this point. 
The recent American Nuclear Society special panel report, "Protection and Management of Plutonium," noted that while nuclear power is likely to be an important component in meeting future energy demand, it does not follow that there needs to be widespread adoption of plutonium recycling. In particular, it seems that the facilities posing the greatest proliferation risk, reprocessing and uranium enrichment plants, do not need to be located outside advanced industrial states with excellent proliferation credentials. Thus, in considering future requirements for nuclear materials safeguards systems, it is possible to think about three general classes of nuclear power use and infrastructure: states with full fuel cycle facilities with reprocessing, enrichment, and possibly breeder reactors; states with MOX-fueled reactors with the fuel supplied by and spent fuel returned to states with full plutonium recycling facilities; and states with reactors using low-enriched uranium fuels only with safeguarded storage of spent fuel or return of spent fuel to supplier states. Therefore, it is not necessary to imagine the need for the most elaborate systems everywhere, but only in selected locations. And while the amount of separated weapons-usable materials is certainly an important parameter for safeguards, the number of geographical locations is probably a more important challenge to the regime.

Safeguards issues for the future can be divided into political/institutional measures and technical measures; however, the two are linked. Advances in safeguards technology can influence institutional measures and political requirements can demand more of technology.

Institutional/Political Measures--Global Nuclear Materials Management

Global nuclear materials management refers to an integrated, systematic approach to thinking about and dealing with nuclear materials and incorporates ideas, not all of which have equal value, that have been proposed for a number of years and in a variety of forms. Although the proposals are grouped under institutional/political measures, most have a strong technical component as well. The primary reason for their categorization as institutional/political is that the barriers to implementation are not primarily technical.

\section{Minimizing Amounts and Locations of Separated Materials}

Although we understand how to effectively safeguard them, the storage of large quantities of direct-use materials for long times at multiple locations should be avoided. Safeguards costs can be reduced by sizing the elements of the fuel cycle to separate only those amounts of attractive materials that are needed, by minimizing the time that those materials are in a direct-use form, and by limiting the number of storage locations. It is important to note, however, that spent fuel still must be safeguarded against diversion by the State (and sabotage by terrorist groups), and that spent fuel becomes more attractive with time as the fission products that provide the radiation barrier decay. Balancing materials supply with demand is made more complex by the economies of scale of building and operating reprocessing plants.

Reprocessing plants that are part of the international nuclear fuel cycle, such as those in the UK and France, must also be prepared to deal with the uncertainties of the flows of materials to and from their facilities through the use of safeguarded and secure interim storage arrangements. 
Materials from nuclear weapons dismantlement, which are attractive to begin with and exist in large quantities, can be dealt with in a variety of ways including special, highly secure storage; timely use in forms that are more proliferation resistant; disposition through reactor or accelerator burning; mixture with high-level waste; or direct deep burial. The near-term concerns for dealing with materials from weapons dismantlement are first to protect them during dismantlement, storage, and ultimate disposition and then to ensure irreversible arms reduction. The nonproliferation benefits accrue from minimizing the terrorist or insider threat to the materials and for showing more intangible aspects of nonproliferation leadership by demonstrating reduced reliance on nuclear weapons.

\section{International (dual key) Control on Sovereign Territory}

Stocks of attractive nuclear materials not needed for immediate processing could be placed under dual access controls of the State and the IAEA. The State would declare its requirements for withdrawals from the store, which would be made under observation by State and IAEA inspectors. The control exercised by the IAEA would not include the right to veto a materials movement, rather it would provide an additional layer of containment and surveillance. Although the materials would be stored on the State's territory and would obviously be under the ultimate control of the State, dual controls would provide an important confidence-building function regarding the State's nonproliferation commitments. Formal mechanisms of this kind have been proposed in the past (for example, international plutonium storage), but never implemented. In practice, with the evolution of continuous surveillance and the possibility of remote monitoring (see Technical Measures section of this paper), the IAEA can have real-time knowledge of materials movements similar to what would be achieved under dual-key control.

\section{Transparency}

Transparency measures are not well defined by the international safeguards community but can include more openness about the purposes of nuclear activities, plans, and inventories of a State as well as more access by inspectorates to facilities, declared and undeclared, in the State. The IAEA's " $93+2$ " program to strengthen safeguards relies on improved access to information and sites that, if granted by the State, will provide considerably increased transparency about the State's nuclear enterprises. Transparency builds confidence and provides information that can be used to more effectively allocate safeguards resources.

\section{Intelligence Sharing}

Although the IAEA can go a long way in improving its ability to detect undeclared activities and materials, it cannot hope to acquire the resources for detecting these activities that are used by many nations. Furthermore, the Agency has no authority to find non-compliance in regard to activities of States not covered by safeguards agreements. Careful intelligence sharing among nations and international organizations, including the IAEA, is therefore an essential element of the nonproliferation regime. Integral to this effort is improving the intelligence communities' ability to detect 
proliferation and in particular, the production, theft, or smuggling of nuclear materials.

Improved States' Systems and Regional Safeguards

Global nuclear materials management begins with the development and implementation of protection and control systems by those with responsibility for the materials: facility operators and the State. Improvements in these systems can make significant contributions to international safeguards in stable regions with cooperative governments. Regional approaches such as EURATOM or ABACC (the joint Brazil/Argentine control commission) also facilitate global controls, serve as important confidence-building measures for nonproliferation, and have economic benefits through the use of shared resources.

\section{Strengthened Physical Protection}

Physical protection for nuclear materials must be balanced to meet the local threat on a global basis. The international safeguards community has made major strides in disseminating physical protection standards, but more can and should be done, possibly including a role for the IAEA as an invited (by the State) independent auditor or assessor of physical protection systems. Advanced monitoring technologies can also play a physical protection function by providing timely warning of diversion even in the international safeguards context.

\section{Proliferation Resistant Measures}

Making nuclear materials inherently less useful for rapid or simple fabrication into a nuclear explosive device can be effective in reducing the terrorist or insider threat. It does not, however, significantly reduce the risk of diversion by the State in the international safeguards context, although it may delay the time from diversion to fabrication. Examples of proliferation resistant measures are the integral fast reactor, in which fission products are never completely separated from plutonium during reprocessing that is integral to the reactor; protecting materials through the use of "natural" barriers such as high radiation fields (for example the National Academy of Science recommendation on the "spent fuel standard,"); and coprocessing of mixed oxide materials ${ }^{3}$. The technical measures are generally well understood; however many policy and political barriers remain.

\section{Supporting the IAEA}

The IAEA and the international safeguards community are only a part of the nonproliferation regime; however, the Agency plays a central role in enhancing international security and the security of all nations. As such, the Agency's costs are a bargain. It is important that the IAEA be provided the

3 Proliferation resistance criteria and the relationship to the "standards" outlined in the National Academy report are described in detail by Debra A. Rutherford, Bryan L. Feary, Jack T. Markin, Donald Close, Keith M. Tolk, Dennis Mangan, and Lonnie More in "Proliferation Resistance Criteria for Fissile Material Disposition Issues," presented at the 36th Annual Meeting of the Institute of Nuclear Materials Management, to be published. 
resources--financial, technical, and personnel--to meet the challenges of a post-cold war world with a growing reliance on nuclear power.

\section{Technical Measures}

The continual evolution of improved technology is the key to cost-effective global nuclear materials management and control. In the face of the growing materials inventories and the number and sophistication of nuclear facilities, both domestic and international safeguards for declared facilities must rely on technology to provide continuous near-real-time knowledge of the amounts, locations, and movements of nuclear materials. To provide assurance that these materials are still where they are supposed to be and have not been stolen or unintentionally released to the environment, they must be measured and inventoried, pathways to the environment must be monitored, and records must be maintained. The detection of undeclared materials or facilities by safeguards inspectorates will rely on sensitive detection methods based on environmental sampling near facilities or over wide areas, as well as on other detection and monitoring approaches.

Nuclear materials control technology has been employed since the beginning of the nuclear age. In the past 30 years much of the emphasis has been on developing methods to detect and measure nuclear materials (primarily uranium and plutonium) rapidly and nondestructively, to improve the precision and accuracy of destructive analysis methods, to provide effective physical protection of materials and facilities, and to ensure the continuity of knowledge about nuclear materials. These technologies span a broad range of instrumentation and systems that includes portable equipment carried by inspectors; on-site instrumentation for use by plant operators; continuous, unattended monitoring and assay equipment for on-site inspection; containment and surveillance measures; and remote monitoring concepts for safeguards, environmental, and proliferation detection applications.

Sensors and monitoring devices are useful only if the information acquired by the instrumentation is organized, analyzed, and displayed in a way that can be used by human decision-makers who must provide assurance that nuclear materials have in fact remained under control. Thus, information management technologies are an integral part of nuclear materials management and control systems.

Although existing technology for nuclear materials control can be used to meet the demands of today's problems, new technology is needed to improve the effectiveness and efficiency of both domestic and international safeguards systems. Nuclear technology is not stagnant, and nuclear materials control technologies must keep up. Instrumentation for safeguarding nuclear materials can be made to provide more timely results, to be more portable, to operate continuously in harsh environments, and to be less expensive. Information management, the key to effective nuclear materials control, is based on the revolution in computer and communications technology. Hardware and software developments for improved analysis of materials inventories and transfer information as well as physical protection or containment and surveillance information have the potential to alert nuclear 
materials managers or inspectors to problems where human analysis would be impossible or not timely.

Trends for future safeguards technical developments can be divided into four categories:

- sensor improvements including, for example, enhanced sensitivity methods for environmental monitoring and measurement methods with improved accuracy for materials accounting;

- information management advances such as detecting anomalies in large databases, computerized materials control and accounting systems, sensor fusion, and remote transmission of large quantities of data;

- integrated, automated, facility-level safeguards systems that provide defense-in-depth such as those currently being demonstrated in the early implementation phase by EURATOM inspectors and plant operators; and

- safeguards effectiveness evaluation methods to provide confidence to safeguards authorities and the public that nuclear materials are in fact under control.

The following sections describe briefly some of the current developments and future trends for safeguards technology; however, this should not be taken to be a comprehensive review of the subject.

Sensors

Needed advances in sensor technology range from improvements in seals to make them more secure, reusable, and remotely readable to the development of nondestructive assay (NDA) methods for the quantitative assay of nuclear materials with improved precision and accuracy that can operate continuously and unattended. Environmental monitoring methods employed to detect undeclared facilities or production also represent advances in sensors for safeguards.

Safeguards applications of seals provide continuity of knowledge about nuclear materials by indicating whether or not an item, container, or portion of a facility has been accessed between inspections or authorized accesses. Simple mechanical seals can only indicate that the seal has been broken (and that access occurred at some time by someone). "Smart" seals have the potential to indicate access times and dates over multiple periods, to identify the user, and to be verifiable in situ or possibly remotely ${ }^{4}, 5$. When coupled with other information, such as video surveillance, it is possible for safeguards authorities to determine authorized access to materials and locations and to detect unauthorized activities. This technology permits authorized plant operations to continue without the continued replacement of seals and improves the overall knowledge of operations. Smart seals can also be employed with automated, unattended material measurement devices to link assay results with item identity without inspectors being present.

4 Steven Kadner and Kevin Ferguson, "The Partnership Approach--New Safeguards Directions," Nuclear Materials Management, XXIII, 1146-1149, (July 1994).

5 P. Chare, P. Detourbet, and W. Kloeckner, "Euratom Experience in Electronic Seal Development," presented at the 5th International Conference on Facility Operations-Safeguards Interface, to be published. 
Physical protection and material control systems rely on sensors to indicate unauthorized or otherwise anomalous activities in nuclear facilities by providing alarms in real time. These types of sensors include intrusion detection systems that are typically deployed on facility perimeters and item and personnel monitoring and tracking systems. Technology development thrusts for these sensors include improving sensitivity and specificity, reducing false alarm rates, reducing costs, data authentication, and improving data transmission characteristics for collection in central alarm stations. Deployment of these sensors can reduce materials inventory frequencies by providing real-time assurance of item integrity and can reduce the threat of unauthorized activities by facility personnel (the "insider threat"). ${ }^{6}$

Surveillance systems based on advances in video and computer technology are being made more reliable and can play a role in real-time monitoring of nuclear facilities. As with many of the other developments in sensor technology, the goal is to ensure the continuing security of nuclear materials or storage locations and thereby reduce inventory frequencies with resulting savings in costs and personnel radiation exposures. In the most straightforward applications, images of static scenes are digitized and compared with the same scene at later times to detect unauthorized access to specific items. By differencing the digitized before and after images, it is possible to detect even small disturbances of items that would be undetectable by human observation. ${ }^{7}$

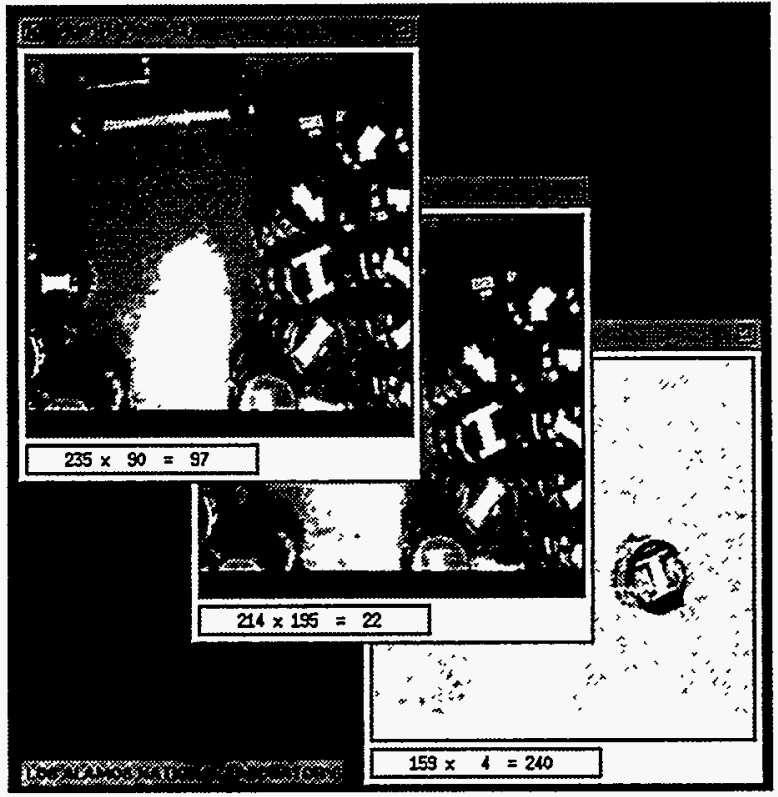

Fig. 2. Digitized video images of a nuclear materials storage vault. A camera views storage containers (drums) from overhead. The before, after, and

6 Denise A. Anspach, Ivan Waddoups, and Eric T. Fox, "Incorporation of Item/Material Attribute System into PAMTRAK," Nuclear Materials Management XXIII, 545-552, (July 1994).

7 Cheryl A. Rodriguez, "Life and Times: The Development of a Digital Video Surveillance System," Nuclear Materials Management XXIII, 273-276 (July 1994) 
difference images are displayed, indicating that one drum was disturbed during a vault access.

Portal monitors, one of the key detection elements in the safeguards systems of nuclear facilities, are designed to detect the unauthorized passage of nuclear materials across specified boundaries. The passage of nuclear materials at facility access points can be monitored with simple hand-held search equipment or fixed detectors designed to monitor personnel or vehicle traffic. Most monitors depend on the detection of gamma radiation to indicate the presence of nuclear materials; however, the addition of neutron detection capability enhances the detection of plutonium. Advances in portal monitor technology include the use of improved detectors, sophisticated electronics and computer software to account for varying backgrounds, and the integration of radiation portals with other portal detection technologies such as metal detectors and access control devices ${ }^{8}$. Through the use of these integrated technologies, portals can be made unattended with remote transmission of alarms.

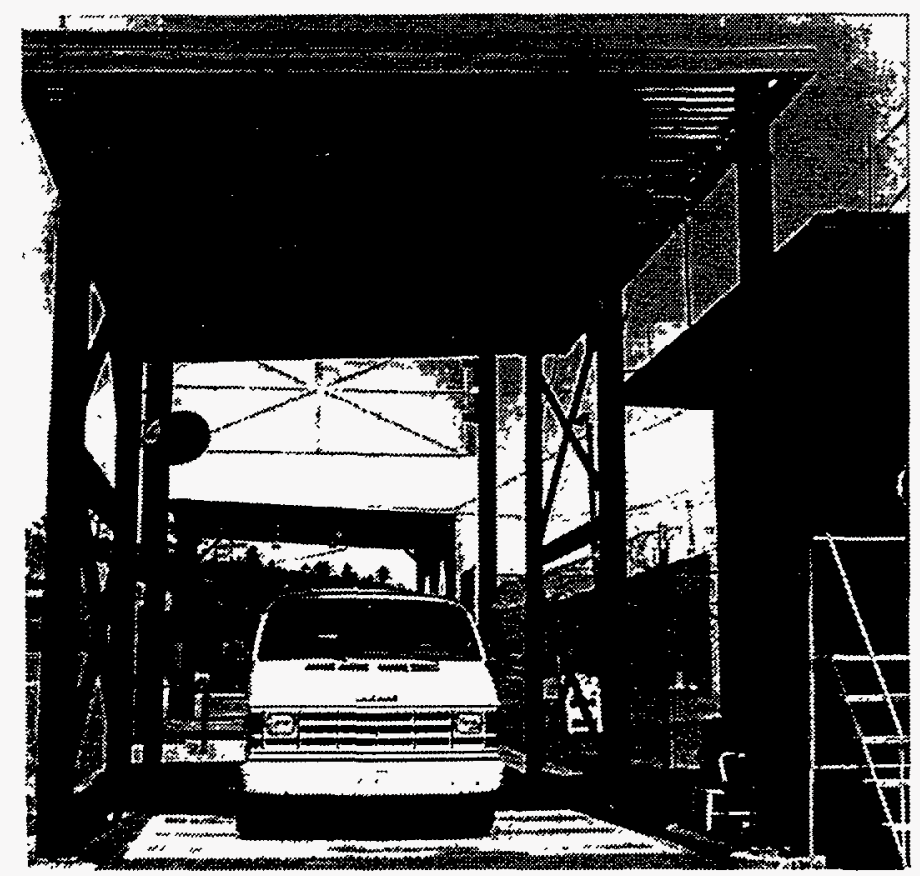

Fig. 3. Vehicle radiation portal monitor. Detectors under the canopy and in the roadbed sense gamma radiation.

Improvements in NDA technology are needed to achieve accuracy requirements for measurements by reducing the sensitivity to bias effects caused by unknown sample characteristics. Gamma-ray tomography is being developed to deal with the assay biases that result from inhomogeneous material distributions in containers of nuclear materials and wastes. Although it is still early in the development of this method, tomographic gamma

${ }^{8}$ R. L. York, P. E. Fehlau, and D. A. Close, "Exporting Automatic Vehicle SNM Monitoring Technology," to be published in the Proceedings of the 5th International Conference on Facility Operations-

Safeguards Interface, American Nuclear Society, September 1995. 
scanning (TGS) has demonstrated the capability to assay 55-gallon drums of heterogeneous materials containing plutonium with accuracies that greatly exceed those achieved in conventional gamma ray scanning. ${ }^{9}$

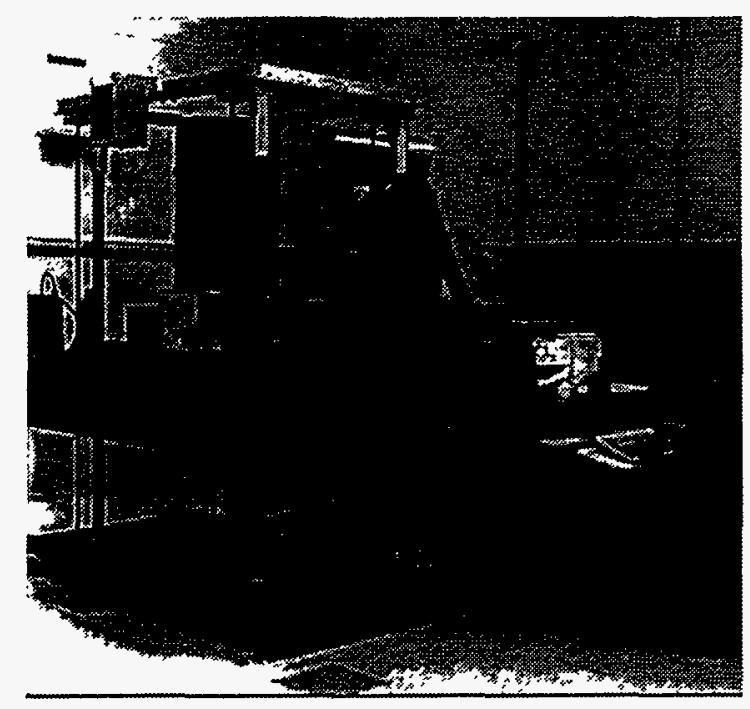

Fig. 4. Prototype Tomographic Gamma Scanner designed to nondestructively determine plutonium content of large containers.

Although tomography is not recommended for all gamma-ray assay applications, it provides the only solution for difficult assay situations, short of unpacking the entire container and conducting nondestructive or destructive analyses on the contents: a very expensive and time-consuming proposition.

Neutron multiplicity analysis provides a similar advance for neutron-based nondestructive assays that can be biased by unknown matrix and multiplication effects. The development of high-efficiency neutron coincidence counters with multiplicity electronics to measure single, double, and triple neutron events (coincidences) provides information that permits the determination of sample mass, neutron multiplication, and (alpha, $n$ ) rate. $^{10}$ Multiplicity counters provide improved accuracy assays and require fewer reference materials to calibrate.

9 T. H. Prettyman, S. E Betts, D. P. Taggart, R. J. Estep, and R. A. Harlan, "Field Experience with a Mobile Tomographic Nondestructive Assay System," presented at the 4th Nondestructive Assay and Nondestructive Examination Waste Characterization Conference, Salt Lake City, Utah, October 1995. 10 N. Ensslin, M. S. Krick, and H. O. Menlove, "Expected Precision of Neutron Multiplicity Measurements of Waste Drums," presented at the 36th Annual Meeting of the Institute of Nuclear Materials Management, Nuclear Materials Management to be published. 


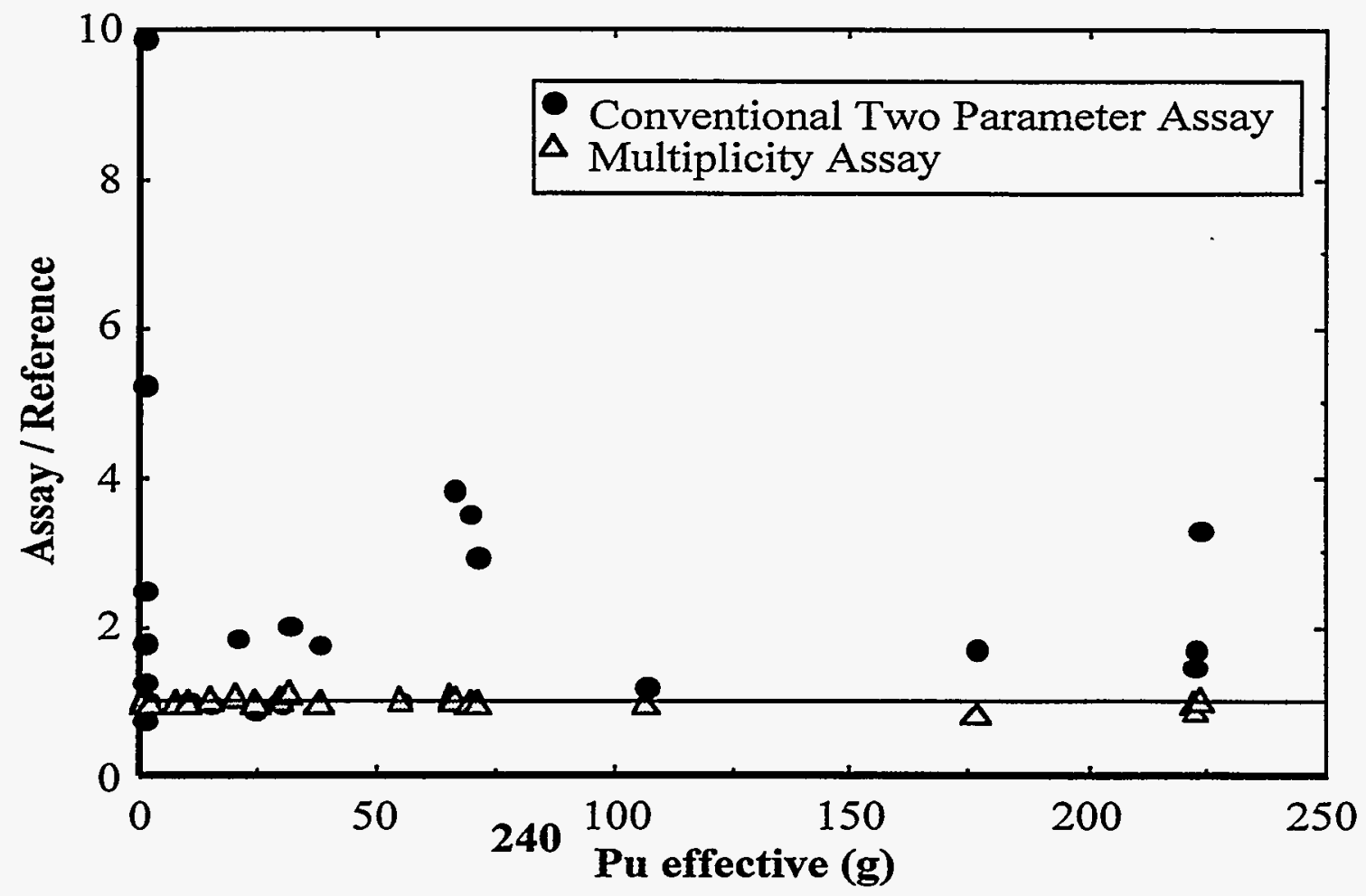

Fig. 5. Ratio of nondestructive assay value to the known reference value plotted vs. the effective ${ }^{240} \mathrm{Pu}$ content of the sample. Multiplicity assay provides significant reduction in assay bias over conventional two-parameter neutron coincidence counting.

Continuous, unattended monitoring and assay systems have the potential to improve the continuity of knowledge by providing timely, low-cost information on amounts and locations of nuclear materials in bulk-handling facilities. For modern, automated nuclear facilities, such instrumentation is the only possible solution to tracking and accounting for nuclear materials throughout the process. The first significant attempt to employ continuous, unattended assay and monitoring equipment was the project undertaken for the Japanese Power Reactor and Nuclear Fuel Corporation (PNC) Plutonium Fuel Production Facility (PFPF) beginning in 1988 to provide a suite of instruments to be installed in the plant and interfaced with the robotic fuel fabrication equipment to provide safeguards information for the IAEA."

"H. O. Menlove, R. H. Augustson, R. Abedin-Zadeh, B. Hassan, S. Napoli, T. Ohtani, M. Seya, and S. Takahashi, "Remote-Controlled NDA Systems for Feed and Product Storage at an Automated MOX Facility," Nuclear Materials Management, XVII, 267-273 (July 1989); M. C. Miller, H. O. Menlove, R. H. Augustson, R. Abedin-Zadeh, T. Ohtani, M. Seya, and S. Takahashi, "RemoteControlled NDA Systems for Process Areas in a MOX Facility," Nuclear Materials Management, XVII, 274-280 (July 1989); S. F. Klosterbuer, E. A. Kern, J. A. Painter, and S. Takahashi, "Unattended Mode Operation of Specialized NDA Systems," Nuclear Materials Management XVII, 262-266 (July 1989). 


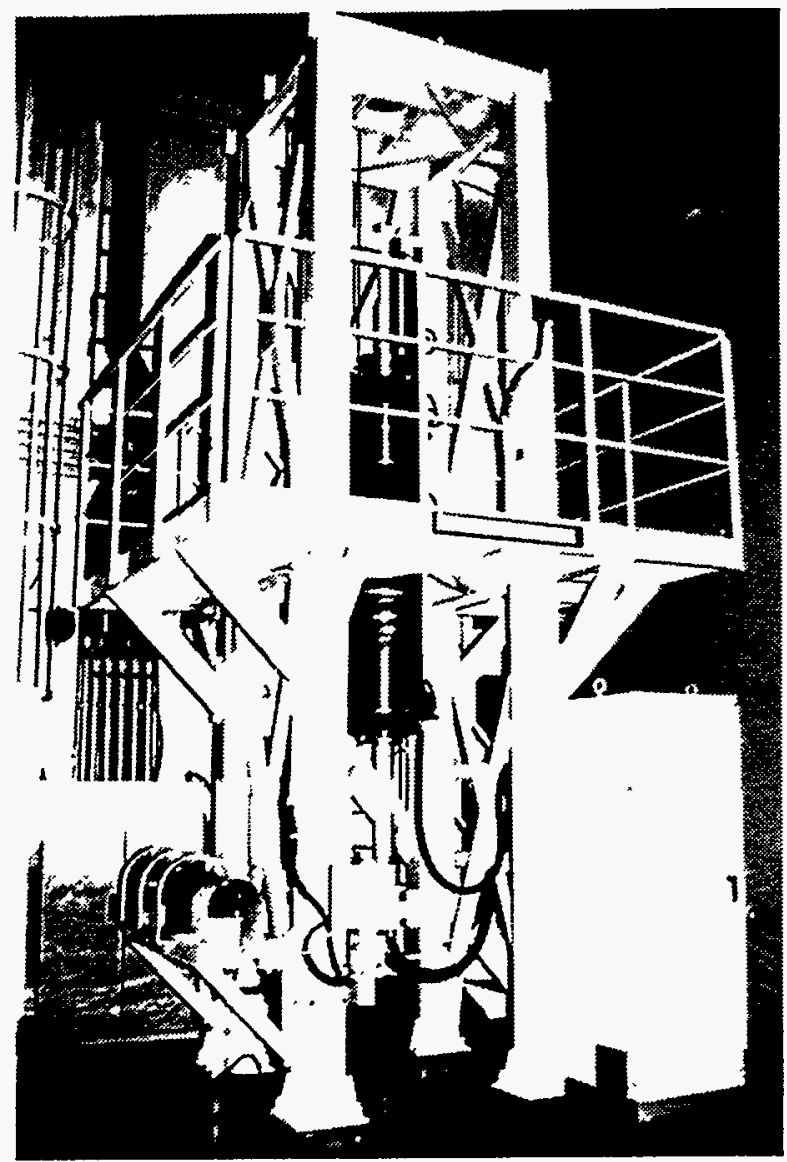

Fig. 6. Nondestructive assay equipment installed at the final fuel assembly transfer point in the Plutonium Fuel Production Facility. Fuel assemblies are moved and plutonium content of assemblies is determined.automatically without inspector presence.

The success of this project has demonstrated the value of using continuous, unattended equipment by improving the knowledge of materials and reducing costs for both the operator and the inspectorate. Reliable communications, hardware, and software are essential for these applications and can be achieved through careful systems engineering, including redundancy. Data authentication is also a key consideration for unattended safeguards systems, and can be achieved through a number of means including encryption and the use of integrated surveillance systems.

Environmental monitoring has only recently been considered for application to international safeguards to detect undeclared materials and activities at declared sites or possibly to detect undeclared facilities. In this context, the monitoring activities include sample collection, packaging, transportation, and analysis using a suite of analytical methods that are, for the most part, well established. Samples include cloth swipes, biota, soil, and water obtained 
at or near nuclear facilities or suspect sites. ${ }^{12}$ In another approach that is based on in-situ detection of alpha particle radiation over long distances, it is possible to detect in real time radioactive materials contamination at very low levels on surfaces in a manner that could be used to detect undeclared activities, materials or facilities. ${ }^{13}$ Environmental monitoring shows great promise for safeguards; however, considerable work is required to incorporate this "sensor" into routine inspection use, and to improve data analysis and interpretation for unambiguous safeguards conclusions.

\section{Information Management}

The management of information is perhaps the most significant area for advancing safeguards technology. The data provided by the sensors described briefly in the previous section is not very useful unless it can be used to make decisions about the status of nuclear materials and the safeguards system. By taking advantage of new computer and communications technologies, safeguards systems can be made to rely less on humans performing mundane tasks, freeing plant operators as well as inspectors and other safeguards personnel for higher-level tasks requiring judgments regarding the performance of the safeguards systems.

Remote monitoring, that is, the transmission of safeguards sensor information to locations removed from the sensors, is a key element for future improvements in the effectiveness and efficiency of safeguards systems, in particular, international safeguards systems. Having large numbers of inspectors on-site is expensive for both the plant operator and the inspectorate. Even when it is desirable to have inspectors on-site, remote monitoring concepts can reduce the numbers required and improve the productivity of the inspectors. Remote monitoring concepts are being developed, field-tested and evaluated to examine and define the technical parameters of remote monitoring systems, to demonstrate the technical feasibility and political acceptability of remote monitoring, to gain acceptance for the concept in the safeguards community, and to identify legal and institutional constraints in the implementation of remote monitoring ${ }^{14}$. Based on an on-site integrated monitoring system (IMS), which brings a suite of local sensor data into a common database though the use of a local network and provides for some local data analysis for data reduction, the remote monitoring system permits the transmission of information, including video surveillance images, to other locations. The greatest challenges to implementing remote monitoring for safeguards are not technical, but institutional and political. Information about nuclear facilities and the status of safeguards at those

12 J. H. Cappis, D. J. Rokop, D. W. Efurd, F. R. Roensch, C. M. Miller, and T.

Benjamin, "Actinide Determination and Analytical Support for Evaluation of Environmental Samples for the IAEA," 17th Annual ESARDA Meeting, to be published.

13 J. E. Koster, J. P. Johnson, and P. Steadman, "Nonproliferation and Safeguarding via Ionization Detection," presented at the 17th Annual ESARDA meeting, to be published.

14 Cecil S. Sonnier, Charles S. Johnson, Sonia Fernandez Moreno, Eduardo D'Amato, Anibal Bonino, John Bardsley, Don Sorokowski, Ken Veveers, Marc Cuypers, Fernand Sorel, Bernd Richter, Gottard Stein, Kinji Koyama, Paul Ek, and Goran af Ekenstam, "The International Remote Monitoring Project--An Update," 17th Annual ESARDA Meeting, to be published. 
facilities has long been considered sensitive by the host nations and not to be transferred in large quantities over communications networks. However, improvements in technology, such as public key encryption, as well as changing political commitments to transparency in nuclear activities, are expected to enable the use of remote monitoring in many applications in the near future. Remote monitoring technologies can also be employed within the nation by inspectorates and reduce costs.

Normally, containment and surveillance sensors, such as radiation monitors and video camera systems, operate independently, providing information to safeguards authorities through independent channels for later analysis by human operators. On-line integration of video digital data, radiation monitoring, and other sensor data promises to increase sensitivity to detecting events of safeguards interest while freeing inspectors or other safeguards authorities from tedious and time-consuming analysis of large quantities of information. Automated pattern-recognition analysis of these integrated safeguards data sets using neural nets and other methods increases evaluation effectiveness by showing trends, discovering anomalies, and highlighting specific activities for detailed review by inspectors. A fundamental problem is the integration of disparate data, for example, from radiation and video sensors. The video data used to monitor movements are spatial in nature; whereas, the NDA sensors provide radiation levels as a function of time. However, changes in video scenes represent movement and can be quantified using a metric that provides motion levels versus time in addition to the spatially oriented video data. In this approach, the video component becomes another detection element as well as a traditional recording instrument. ${ }^{15}$ Another approach to sensor fusion that is being applied to exterior intrusion detection systems is the use of "fuzzy" sets and "genetic" algorithms to combine information from three sensors to increase the reliability and confidence of distinguishing between real and false alarms. ${ }^{16}$ Future developments in combining signals and information from disparate sources in real time will be crucial to the effective operation of integrated safeguards systems.

Modern nuclear materials storage facilities will incorporate elaborate sensor suites to monitor conditions of importance to the environment and to the safety and health of the workers. In addition, both domestic and international safeguards systems could use this sensor information. Using common sensors and databases, a single integrated system can provide information to multiple users, thus reducing costs and intrusions on facility operations. The primary technical challenge is providing the right information to the right user, who may be at a remote location, while protecting any sensitive information from unauthorized disclosure. Applications of common communications systems, such as the Internet, and the use of information security systems, are being

15 J. A. Howell, H. O. Menlove, C. A. Rodriguez, D. Beddingfield, A. Vasil, "Analysis of Integrated Video and Radiation Data," presented at the 36th Annual Meeting of the Institute of Nuclear Materials Management, Nuclear Materials Management, to be published.

16 Deborah S. Fitzgerald and Douglas G. Adams, "Adaptive Sensor Fusion Using Genetic Algorithms," Nuclear Materials Management XXIII, 346-351 (July 1994). 
demonstrated and show promise for the use of these technologies in the future. ${ }^{17}$

Local area networks can provide the basis for a computerized near-real-time material accounting system that captures the accounting data as close to the source of that data as possible. ${ }^{18}$ Process operators can enter the data directly into the system immediately after each reportable occurrence; process control systems can also provide data in real time. The database of material information is updated as soon as the information is entered. Implemented using a client/server approach, these systems take advantage of the reduction in computer hardware costs by using a powerful server to maintain the material database and personal computer "clients" to provide the user interface.

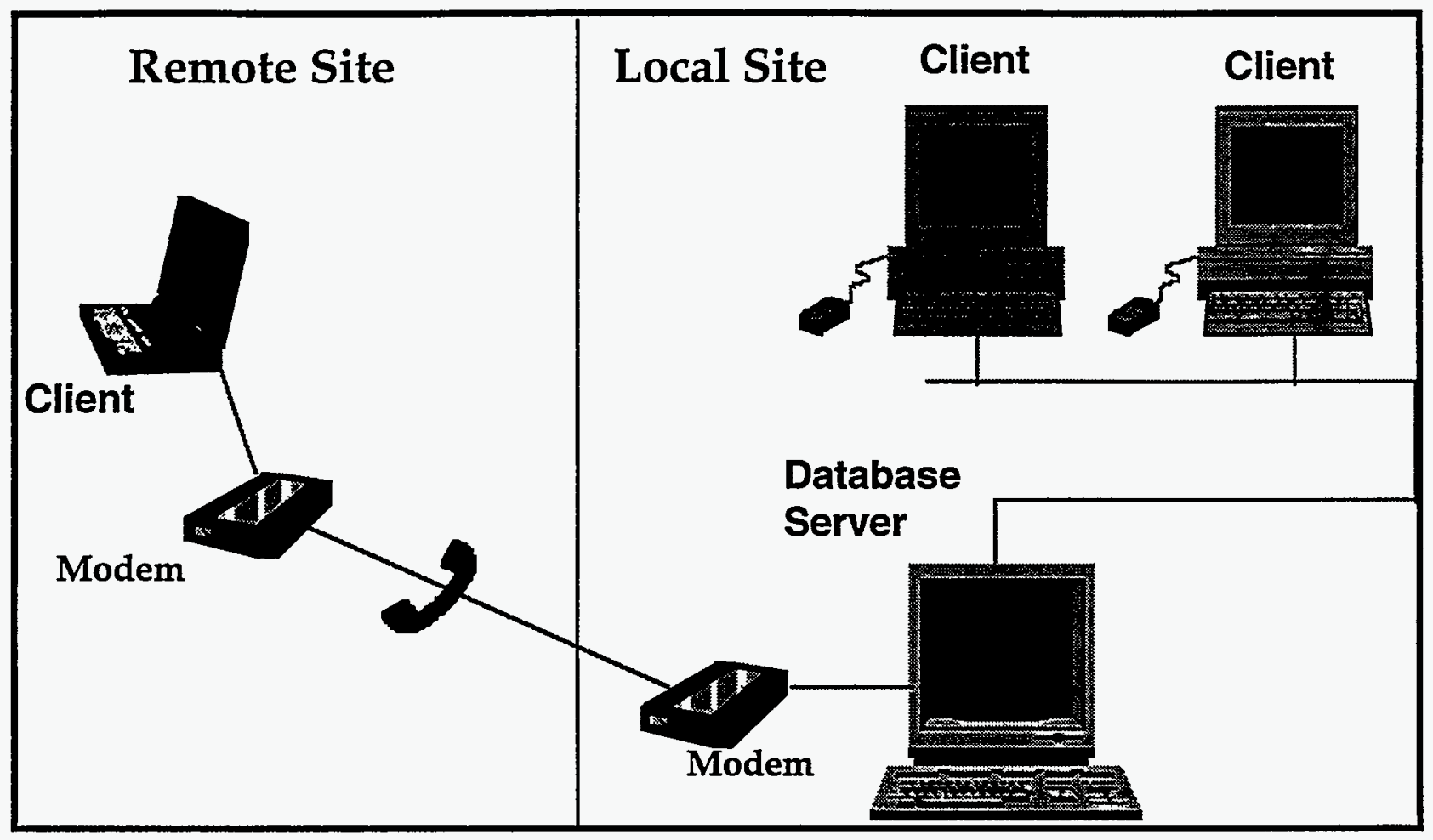

Fig. 7. Conceptual Local Area Network Material Accounting System.

Advances in sensors and databases permit the accumulation of vast quantities of information about nuclear materials and the operation of nuclear facilities. The majority of this information is indicative of normal operations of no safeguards concern. The challenge for the safeguards systems is to find

17 Curt Nilsen and Dennis Mangan, "Straight-Line: A Nuclear Material Storage Information Management System," presented at the 36th Annual Meeting of the Institute of Nuclear Materials Management, Nuclear Materials Management, to be published.

18 Joe Claborn and Al Alvarado, "LANMAS Core: Update and Current

Directions," ," 35th Annual Meeting Proceedings of the Institute of Nuclear Materials Management, Nuclear Materials Management, XXIII, p313-317, (July 1994) 
information that may indicate an attempted diversion or theft of nuclear materials buried within a mountain of other data. The first step in analyzing safeguards data is to identify anomalies--something that is not normal. Within the set of anomalous events lie the indicators of events of safeguards significance. Anomaly detection schemes can be applied to inventory difference data from materials accounting to identify losses of materials, to sensor data to improve alarm detection performance, and to large databases of materials transaction information to indicate process upsets or diversions. Approaches to anomaly detection include classical statistical methods, ${ }^{19}$ the use of fuzzy logic, ${ }^{20}$ neural networks, ${ }^{21}$ and rule-based expert systems. ${ }^{22}$ Process modeling and simulation can also be used to predict future behavior of systems and to detect deviations from the expected condition of processes. ${ }^{23}$ Advances in computing and similar information management requirements in many other fields are expected to make significant contributions to the detection of anomalies in safeguards information systems.

\section{Facility Monitoring and Safeguards Systems}

The ability to safeguard nuclear materials in large bulk-handling facilities such as mixed oxide (MOX) fuel fabrication plants and reprocessing plants of the kind being operated in Europe and under construction in Japan depends on developing and implementing systems that go far beyond the materials accounting and containment/surveillance measures that were adequate for the facilities of the early commercial nuclear fuel cycle. To provide confidence in safeguards for these new plants, it is necessary to employ a defense-in-depth approach that goes well beyond a periodic determination of material unaccounted for (MUF) and a review of $\mathrm{C} / \mathrm{S}$ data. Large numbers of sensors integrated into real-time information management systems must be employed and operated by the facility operators under the supervision of national or regional authorities and under the inspection of international agencies. The systems must be designed into the plants with the cooperation of the operator and must provide a degree of redundancy and overlap such that no one component is the weak link in the system.

19 Tom L. Burr, "Predicting Linear and Nonlinear Time Series with Applications in Nuclear Safeguards and Nonproliferation," Los Alamos National Laboratory report LA-12766-MS (April 1994).

${ }^{20}$ Andrew Zardecki, "Fuzzy Controllers in Nuclear Material Accounting," Fuzzy Sets and Systems 74, 73-79 (1995).

21 J. A. Howell, H. O. Menlove, G. W. Eccleston, R. Whiteson, C. A. Rodriguez, J. K. Halbig, S. F. Klosterbuer, and M. F. Mullen, "Safeguards Applications of Pattern Recognition and Neural Networks," IAEA Symposium on International Safeguards, IAEA-SM-333/112, Vienna, 14-18 March 1994.

22 Rena Whiteson, Lisa Spanks, Tresa Yarbro, Ferman Kelso, Janet Zirkle, and Chris Baumgart, "Anomaly Detection Applied to a Materials Control and Accounting Database," presented at the 36th Annual Meeting of the Institute of Nuclear Materials Management, Nuclear Materials Management, to be published.

${ }_{23}$ C. Alton Coulter, Rena Whiteson, and Andrew Zardecki, "Simulation Study of Near-Real-Time Accounting in a Generic Reprocessing Plant," Nuclear Materials Management XXI, 486-489 (July 1992). 
Faced with the operation of a number of large scale facilities processing significant quantities of plutonium, the EURATOM safeguards inspectorate has developed sophisticated integrated safeguards systems for a number of plants in France and the United Kingdom. ${ }^{24}$ Although each system is designed around its facility and employs plant-specific instrumentation, EURATOM and the plant operators have developed a common approach to this challenging problem that employs many of the latest developments in safeguards equipment and concepts and builds on safeguards research and development advances of the 1970 s and 1980 s including, for example, the continuous, unattended monitoring and assay approaches pioneered in the PFPF in Japan mentioned previously. These systems must contend with the high degree of automation employed in modern nuclear processing facilities to reduce radiation exposure to workers and inspectors; however, automation presents an opportunity if the safeguards system can utilize information provided by the plant process monitoring equipment.

The approach to safeguarding these plants is to make use of the large quantities of information available about the flows and inventories of nuclear materials from both independent measurement and detector systems, as well as plant equipment, by employing authentication and verification measures at differing levels of independence. Also key to the success of safeguards for large scale plutonium processing facilities is the use of inspectorate-staffed on-site laboratory facilities to provide timely analysis results for samples while avoiding the costly and time-consuming transport of plutonium samples to central laboratories.

For the thermal oxide reprocessing plant (THORP) operated by British Nuclear Fuels plc (BNFL), the enhanced approach is "based on

-A high degree of transparency of operations by the provision by the operator in near real time of a well chosen operating data set, verified by EURATOM according to a hierarchy of control levels;

-Comprehensive (i.e., 100\%) quantitative flow verification techniques at key points;

-Application of integrated monitoring and containment/surveillance (C/S) techniques for additional internal flow verifications and maintenance of continuity of knowledge;

- Continuous presence of highly trained inspectors fully familiar with the design and operation of the plant as well as the safeguards measures employed."25

${ }^{24}$ W. Gmelin and W. Kloeckner, "Safeguards in Europe--An Update," Y. Paternoster, S. Kaiser, P. Chare, Ph Dossogne, Ph. Beaudoin, P. Molinari, J. Regnier, "Safeguards Activities During the Commissioning Phase of the MELOX MOX Fuel Fabrication Plant," P. Chare, A. Dutrannois, W. Kloeckner, and M. T. Swinhoe, "Networking of Safeguards Systems," presented at the 5th International Conference on Facility Operations-Safeguards Interface, to be published.

${ }^{25}$ S. Kaiser, H. Nackaerts, R. Schenkel, P. J. Chare, H. G. Wagner, R. Howsley, and E. Williams, "Thorp: Authentication, Transparency and Independence," Proceedings of the IAEA International Safeguards Symposium, Volume 2, Vienna, 1994. 
This approach provides a higher degree of assurance about the nuclear materials and the absence of diversion than could ever be generated by the materials accounting data and statistical analysis alone. It is the operation of these systems and their promise for other new facilities that give safeguards professionals the confidence that safeguards technology and systems implementation can meet the demands of the growing nuclear fuel cycle, including plutonium recycling.

\section{Safeguards Effectiveness Evaluation Methods}

As noted in the previous section, modern safeguards systems for large bulkhandling facilities employ a defense-in-depth approach that goes far beyond the use of materials accounting data alone or the examination of $\mathrm{C} / \mathrm{S}$ records to determine if materials have been diverted. It is important, especially in the context of international safeguards, for safeguards authorities to be able to assess the overall effectiveness of these integrated safeguards systems to assure the public and governments that materials are under control and that States are in compliance with their safeguards commitments. Performance measures based on a statistical analysis of materials accounting data are attractive because they are quantitative and require no independent judgment that could be politically motivated. However, these straightforward measures, even when coupled with assessments of inspection effort and $C / S$ data, do not seem adequate to determine in a uniform fashion that safeguards systems are performing up to standards. This problem, how to combine information from multiple sources to reach conclusions, is of course, related to the problems described in the information management section of this paper regarding combining data from multiple sensors. ${ }^{26}$ In this case; however, the need is to examine the entire safeguards system and the validity of the conclusions based on the system. The safeguards community has not accepted any single approach to assessing the performance of safeguards systems, and "expert" . judgment still plays a large role. Although the expert's opinions will always be important, further research and application of theories of information combination appear to be warranted for assessment of safeguards systems.

\section{Conclusions}

Safeguards technology development, supported by research and development programs in the U.S. ${ }^{27}$ and overseas, continues to improve the effectiveness and efficiency of safeguards system. When coupled with new institutional arrangements, these technologies are able to keep pace with the growing inventories of declared nuclear materials in safeguarded facilities to provide assurance that materials from the power reactor fuel cycle are not being diverted to military explosives. Defense-in-depth approaches that use the latest in sensor and information management technologies can deal with the high-throughput fuel cycle facilities, as demonstrated in facilities in the UK and France. The detection of undeclared facilities, although of great importance to the nonproliferation regime and international safeguards, is not a significant consideration for safeguards on declared facilities and is

26 Clint Scovel, "The Combination of Information," to be published ?

27 In the U.S., the Department of Energy Office of Nonproliferation and National Security is a major supporter of safeguards research, development, and implementation. The Department of State provides support for implementation of IAEA safeguards. 
being improved through the use of, for example, environmental monitoring. With continued technology and institutional development as well as measured growth of the nuclear fuel cycle in a responsible fashion to limited regions, nuclear materials safeguards can meet the challenges of the future. These technologies and institutions also have the potential to facilitate other nuclear materials control regimes, including the international inspection of excess weapons materials in the nuclear weapons states and the verification of a fissile materials production cutoff convention.

\section{Acknowledgments}

I would like to thank Joe Pilat, Don Close, Tom Burr, Rich Strittmatter, Avigdor Gavron, Joe Claborn, JoAnn Howell, and Debbie Rutherford, for their assistance with this paper; Paul Henriksen for editing the manuscript, Charlene McHale for helping to keep the paper preparations on track and for her excellent word-processing skills. As author, I remain solely responsible for its content. The views expressed are my own, and not necessarily those of the University of California, the U.S. Government, or any other institution. 